\title{
Unsuspected difficulty using a laryngeal mask airway and a video laryngoscope due to unanticipated congenital pharyngeal bands
}

\author{
Guanrong Zheng, MD (1) - Dalong Wang, MD - Daozhou Xu, MD
}

Received: 27 June 2015/Revised: 2 July 2015/Accepted: 15 July 2015/Published online: 7 August 2015

(c) Canadian Anesthesiologists' Society 2015

\section{To the Editor,}

This letter illustrates an unusual case of difficulty using a laryngeal mask airway $\left(\mathrm{LMA}^{\mathrm{TM}}\right)$ and a video laryngoscope due to multiple abnormal pharyngeal and pharyngolaryngeal bands in a 62-yr-old female with chronic otitis media presenting for elective tympanoplasty. Her medical history revealed no significant infectious or other systemic disease or any airway trauma. The patient granted consent for publication of this report. At presentation to our otorhinolaryngology clinic, examination of the patient's upper airway using an indirect laryngeal mirror and revealed no laryngeal congestion. Furthermore, the patient's tonsils were normal bilaterally, the uvula was visualized, and other laryngeal reflexes were present. The epiglottis was not easily visible, though the appearance and movement of the bilateral faucial pillars and vocal cords were normal. The preanesthesia evaluation revealed no significant physical or laboratory abnormalities. The patient's neck was relatively short but freely moveable; her mouth opening was more than three finger-widths; no protruding incisors or other obvious signs were present to suggest a difficult airway, and the Mallampati classification was 2 .

In the operating room, preoxygenation was performed via face mask, and general anesthesia was subsequently induced with intravenous midazolam $2 \mathrm{mg}$, sufentanil 20 $\mu \mathrm{g}$, propofol $40 \mathrm{mg}$, and atracurium $10 \mathrm{mg}$. Ventilation

G. Zheng, MD $(\varangle) \cdot$ D. Wang, MD

Department of Anesthesiology, Central Hospital of Shengli

Oilfield, Dongying, Shandong, China

e-mail: zhgrong924@sina.cn

D. Xu, MD

Department of Magnetic Resonance, Central Hospital of Shengli Oilfield, Dongying, Shandong, China proceeded smoothly through the face mask. After confirmation of adequate muscle relaxation, a size-3 LMA Supreme ${ }^{\mathrm{TM}}$ (Teleflex Inc, Research Triangle Park, NC, USA) was inserted into the patient's mouth as per routine. Unfortunately, great resistance was encountered at the level of the base of the tongue, and despite three attempts, the LMA could not be advanced further into an adequate supraglottic position. Direct endotracheal intubation was attempted using a Tosight B-type video laryngoscope (ShangHai Tosight Electronics Technology Co., Ltd., China); however, laryngoscopy revealed multiple fibrotic bands occupying the bilateral faucial pillars, which hindered the laryngoscope from being advanced to the larynx (Figure, upper panel). Accordingly, an F1-13RBS flexible bronchoscope (Pentax Medical Company, Japan) was used with a size-7.0 endotracheal tube to assist endotracheal intubation through the nasal route without difficulty. Ventilation via the face mask in this patient continued without any difficulty throughout the period.

The operation proceeded smoothly and the patient recovered without incident. Nine days after the operation, her larynx was topically anesthetized and carefully reexamined with a video laryngoscope (Visera OTV-S7 Digital Processor, Olympus Company, Japan) (Figure, lower panel).

One common cause of difficult intubation is the structure of the patient's airway. In our patient, the routine preanesthesia evaluations, which included a standard physical examination and medical history, did not predict a difficult airway. According to recent recommendations ${ }^{1}$ for managing a difficult airway, when failed tracheal intubation is apparent, an exit strategy should be established before multiple attempts at intubation. Even so, the chosen technique should be suited to the context of the individual patient's anatomy 

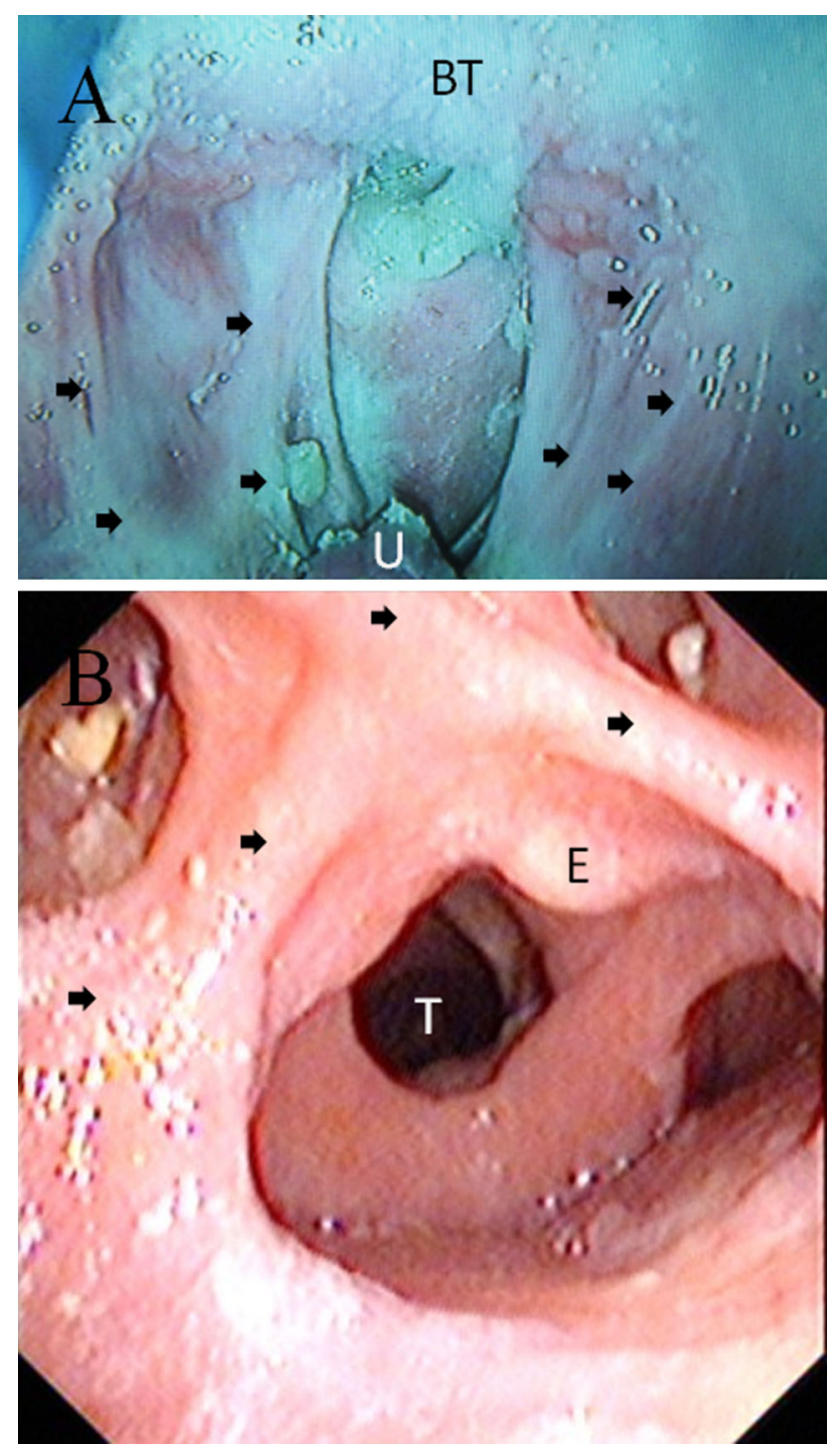

Figure A) Image of the patient's pharynx on laryngoscopy using a Tosight laryngoscope. Instead of normal faucial pillars, there is a muscular pharyngolaryngeal band on either side extending from the base of the tongue (BT) to the lateral pharyngeal walls and the uvula (U). The soft palate was fused to the posterior pharyngeal wall with multiple pharyngeal bands (arrows), which impeded insertion of a laryngeal mask airway and tracheal intubation. Bilateral tonsils were small but present. B) Image of the patient's larynx using an Olympus video laryngoscope. The anterior and posterior walls of the pharynx were tethered by multiple pharyngolaryngeal bands (arrows). The epiglottis (E) was short and tethered to the posterior pharyngeal wall by bands from its lateral aspects. The trachea $(\mathrm{T})$ was normal and pathophysiology, operator familiarity, and the practice environment. Our patient had anomalies in the airway that impeded the use of a video laryngoscope. Based on the clinical appearance (and later magnetic resonance imaging studies), multiple abnormal pharyngeal and pharyngolaryngeal bands were seen. The presence of pharyngeal and pharyngolaryngeal bands is a rare congenital abnormality. ${ }^{2,3}$ It is postulated that these arose from a failure of the second branchial pouch to develop.

Conflicts of interest None declared.

\section{References}

1. Law JA, Broemling N, Cooper RM, et al. The difficult airway with recommendations for management-Part 1-Difficult tracheal intubation encountered in an unconscious/induced patient. Can J Anesth 2013; 60: 1089-118.

2. Prescott $C A$. Pharyngeal and pharyngolaryngeal bands: report of an unusual combination of congenital anomalies. Ann Otol Rhinol Laryngol 1995; 104: 653-4.

3. Fayoux $P$, Vachin F, Merrot $O$, Chevalier D, Robert $Y$. Congenital pharyngolaryngeal band: report of an unusual case of respiratory distress. Int J Pediatr Otorhinolaryngol 2003; 67: 1379-81. 